\title{
Quality of Life after Functional Endoscopic Sinus Surgery in Patients with Chronic Rhinosinusitis
}

\author{
Sadaf Qadeer ${ }^{1}$, Shabbir Akhtar², Montasir Junaid ${ }^{3}$, Muhammad Sohail Halim ${ }^{4}$ \\ ${ }^{1}$ Department of Otolaryngology-Head \& Neck Surgery, Sir Syed College of Medical Sciences, Karachi, Pakistan \\ ${ }^{2}$ Department of Otolaryngology-Head \& Neck Surgery, Aga Khan University \& Hospital, Karachi, Pakistan \\ ${ }^{3}$ Department of Otolaryngology-Head \& Neck Surgery, Armed Forces Hospital Southern Region, Khamis Mushayt, KSA \\ ${ }^{4}$ Stanford University, Palo Alto, USA \\ Email: *sadaf.qkhan@gmail.com
}

How to cite this paper: Qadeer, S., Akhtar, S., Junaid, M. and Halim, M.S. (2018) Quality of Life after Functional Endoscopic Sinus Surgery in Patients with Chronic Rhinosinusitis. International Journal of Otolaryngology and Head \& Neck Surgery, 7, 189-198.

https://doi.org/10.4236/ijohns.2018.74020

Received: April 24, 2018

Accepted: July 13, 2018

Published: July 16, 2018

Copyright $\odot 2018$ by authors and Scientific Research Publishing Inc. This work is licensed under the Creative Commons Attribution International License (CC BY 4.0).

http://creativecommons.org/licenses/by/4.0/

\begin{abstract}
Chronic Rhinosinusitis (CRS) is a group of disorders characterized by the inflammation of mucosa of the nasal passages and paranasal sinuses. It includes chronic rhinosinusitis with polyps, CRS without polyps and Allergic Fungal Sinusitis (AFS). This debilitating disease causes negative impact on quality of life (QOL) of patients. Functional endoscopic sinus surgery (FESS) is the mainstay of surgical treatment for patients and improves QOL of patients. This subjective assessment of QOL can be measured by disease specific questionnaires. SNOT-22 questionnaire is widely used and validated questionnaire for this purpose. Prospective study was done on 54 patients. Data were collected using SNOT-22 questionnaire and filled in pre-operative period then in post-operative follow-up visits on $1^{\text {st }}, 3^{\text {rd }}, 6^{\text {th }}$ and $12^{\text {th }}$ months. Paired sample $\mathrm{t}$-test was used to compare pre-operative and post-operative SNOT scores and multivariate generalized linear model was used to estimate regression parameters for SNOT scores in CRS with polyp and AFS in comparison of CRS without polyps. Out of 54 patients, $59.3 \%$ were males, mean age was 35.98 , $29.6 \%$ were in CRS without polyp group, $44.4 \%$ and $25.9 \%$ were in CRS with polyps and AFS group. Recurrence occurred in $7.4 \%$, revision surgery required in $3.7 \%$ while $22.2 \%$ had history of asthma. Paired sample t-test showed statistical significant reduction in post-operative SNOT scores. Linear model results showed SNOT scores in CRS with polyp group was significantly reduced. Thus FESS provides significant improvement in QOL of patients in chronic rhinosinusitis.
\end{abstract}

\section{Keywords}

Quality of Life, Chronic Rhinosinusitis, Surgery 


\section{Introduction}

Chronic Rhinosinusitis (CRS) is a group of disorders characterized by the inflammation of mucosa of the nasal passages and paranasal sinuses lasting for duration of 12 weeks or longer [1] [2]. It is a broad terminology that encompasses three common subtypes which are Chronic Rhinosinusitis with polyps, CRS without polyps and Allergic Fungal Sinusitis (AFS) [2]. The differentiation among the subsites is based on clinical examinations, histopathological findings and prognosis [3]. Chronic Rhinosinusitis is a debilitating disease which results in large financial burden over society [4]. It was estimated that approximately 20 million patients are affected by this disease with an average of 1 per 7 individuals in United States [5] [6]. Chronic Rhinosinusitis gives negative impact on quality of the life (QOL), impairs daily activities of patients which leads to substantial health care expenditures. Due to its increasing incidence and prevalence, it is essential to evaluate regarding the disease and its treatment outcome [7]. The main aim of the management of chronic rhinosinusitis is to open the airway, improvement of the smell, elimination of polyps and improvement in the quality of life of patients. Chronic rhinosinusitis with or without polyps are dealt with medical therapy as first line of treatment including antibiotics, saline irrigation, topical and systemic glucocorticoids and inter leukotriene agents and surgery is reserved for those patients who fail to respond to medical treatment while allergic fungal sinusitis requires surgery as initial management [8]. Functional endoscopic sinus surgery (FESS) is considered as a gold standard surgical management for chronic rhinosinusitis. In literature, there has been found a positive and great impact on quality of life of patients who underwent FESS [8] [9].

Quality of life is a term integrating several aspects such as physical, psychological, social, economic and emotional dimensions. The disturbance in any one of these aspects will in turn affect QOL significantly. In last two decades, researchers have shown interest in assessing QOL by developing QOL related questionnaires [10]. SNOT-22 is the most suitable and reliable disease specific questionnaire designed for use in chronic rhinosinusitis patients. It is a patient-reported outcome measure of symptom severity and quality of life in patients with sinonasal diseases [10] [11].

Functional endoscopic sinus surgery (FESS) is routinely performed in our tertiary care hospital and patients are followed up in clinic on intervals for clinical endoscopic nasal examinations but patients were never been asked specifically for the improvement in their symptoms after surgery with the help of disease specific questionnaire. Therefore, this study is aimed to evaluate the symptomatic improvement in patients quality of life (QOL) after functional endoscopic sinus surgery (FESS).

\section{Objective}

To compare the quality of life after functional endoscopic sinus surgery in patients with subtypes of chronic rhinosinusitis. 


\section{Material and Methods}

The prospective study was carried out in the department of Otolaryngology at Aga Khan University \& Hospital, for a period of one and a half year from October 2012 to April 2014, after taking approval from ethical review committee of the institute.

The patients with age $\geq 18$ years who were failed to respond to medical therapy and underwent functional endoscopic sinus surgery (FESS) for three main sub types of chronic rhinosinusitis (CRS) such as chronic rhinosinusitis without polyps, CRS with polyps and Allergic fungal sinusitis were included in the study. The patients who had previous history of nasal surgery, revision FESS, associated malignant disease of nose and paranasal sinuses or any history of systemic disease were excluded. Sample size of 52 was calculated using WHO calculator. A total of 60 patients of chronic rhinosinusitis who consented to participate in the study were enrolled but six patients did not complete the follow ups hence excluded from the study and final end sample was a total of 54 patients.

The data were collected for age, gender, diagnosis, asthma, recurrence of disease and revision surgery. SNOT-22 questionnaire (Appendix 1) was filled to assess quality of life of patients by single interrogator on preoperative visit to clinic then same questionnaire was filled over post-operative follow up visits on $1^{\text {st }}, 3^{\text {rd }}$, $6^{\text {th }}$ and $12^{\text {th }}$ months.

SNOT-22 QUESTIONNAIRE:

SNOT-22 (Sino Nasal Outcome Test-22) is a validated 22-item CRS-specific quality of life instrument which is scored by using Likert scale where $0=$ No problem, $1=$ Very mild problem, $2=$ Mild or slight problem, $3=$ Moderate problem, $4=$ Severe problem and $5=$ as bad as it can be. Higher scores on the SNOT-22 items signify worse condition or symptoms severity. Total score range is from 0 to 110 [11].

\section{DATA ANALYSIS:}

Data were stored and analyzed using IBM-SPSS version 23.0, count and percentages were given for Gender, Diagnosis, Recurrence, Revision of Surgery and Presence of Asthma, mean and standard deviation were reported for the age, Intra operative time in minutes, and SNOT scores at pre operative stage and follow-ups. paired sample t-test was used to compare the pre operative SNOT scores with $1^{\text {st }}, 3^{\text {rd }}, 6^{\text {th }}$, and $12^{\text {th }}$ month SNOT scores, Multivariate Generalized linear model was used to estimates the regression parameters for SNOT scores in CRS with polyp and Allergic fungal sinusitis, in comparison of CRS without polyp cases, p-values less than 0.05 were considered significant. Bar chart, and line chart also used to give the graphical presentation of data findings.

\section{Results}

In the present study, out of 54 patients, $59.3 \%(\mathrm{n}=32)$ were males, the mean age was $35.98 \pm 7.68$ years, $29.6 \%(\mathrm{n}=16)$ patients were diagnosed and grouped in CRS without polyp, $44.4 \%(\mathrm{n}=24)$ patients were included in CRS with polyps 
and $25.9 \%$ (n-14) patients were diagnosed as Allergic fungal sinusitis, recurrence of disease occurred in $7.4 \%$ patients $(n=4)$ and revision surgery was required in $3.7 \%$ patients $(n=2)$ and the other two patients who had recurrence were managed conservatively while $22.2 \%(n=12)$ of patients had history of asthma (Table 1).

Results of paired sample t-test showed that the preoperative SNOT scores were higher but after FESS they reduced significantly at $1^{\text {st }}, 3^{\text {rd }}, 6^{\text {th }}$ and $12^{\text {th }}$ months post operatively (Figure $1 \&$ Table 2).

The multivariate generalized linear model were performed to establish the difference of the changes in the SNOT-22 Scores overtime and the results of the model showed that, pre-operative SNOT scores significantly increased in CRS with polyp and Allergic fungal sinusitis as compare to CRS without polyp, SNOT

Table 1. Baseline characteristics of studied sample $(n=54)$.

\begin{tabular}{|c|c|c|c|}
\hline \multicolumn{2}{|c|}{ Parameters } & \multirow{2}{*}{$\begin{array}{c}\mathbf{n} \\
32\end{array}$} & \multirow{2}{*}{$\begin{array}{c}\% \\
59.3\end{array}$} \\
\hline \multirow{3}{*}{ Gender } & Male & & \\
\hline & & & \\
\hline & Female & 22 & 40.7 \\
\hline \multirow{3}{*}{ Diagnosis } & CRS without polyp & 16 & 29.6 \\
\hline & CRS with polyp & 24 & 44.4 \\
\hline & Allergic fungal sinusitis & 14 & 25.9 \\
\hline \multirow{2}{*}{ Recurrence } & Yes & 4 & 7.4 \\
\hline & No & 50 & 92.6 \\
\hline \multirow{2}{*}{ Revision surgery } & Yes & 2 & 3.7 \\
\hline & No & 52 & 96.3 \\
\hline \multirow{2}{*}{ Presence of asthma } & Yes & 12 & 22.2 \\
\hline & No & 42 & 77.8 \\
\hline Age (Years) & Mean, SD & 35.98 & 7.68 \\
\hline Intra operative time in minutes & Mean, SD & 61.98, & 15.05 \\
\hline
\end{tabular}

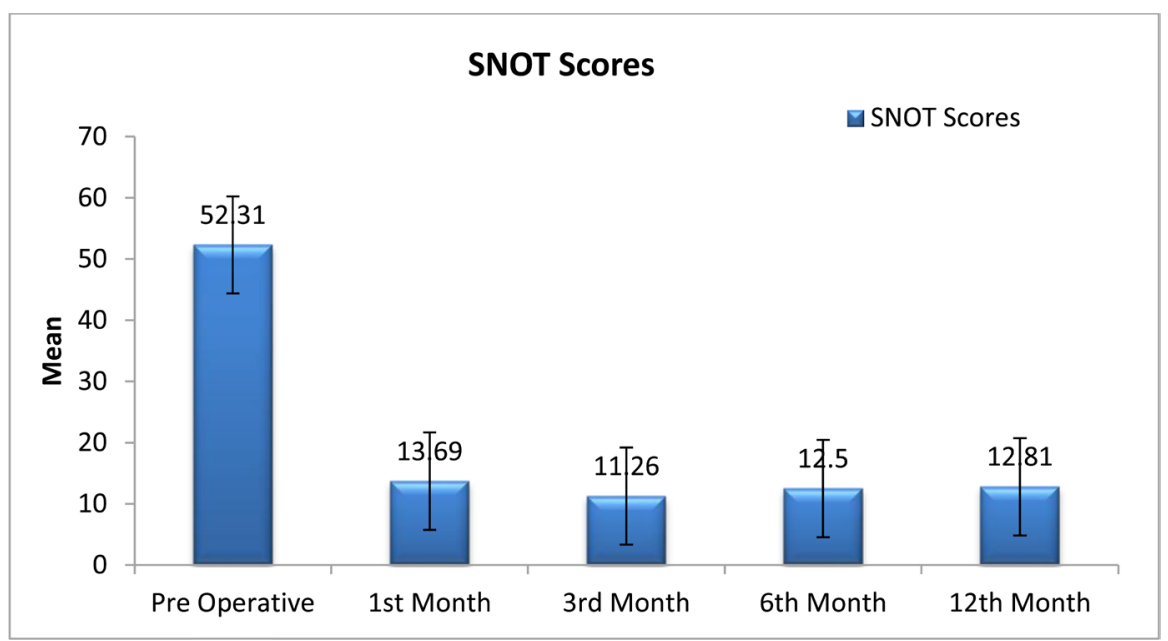

Figure 1. Pre-operative and Post-operative SNOT scores. 
Scores of $1^{\text {st }}$ month went further decrease in CRS with polyp case and less reduction was found in allergic fungal sinusitis cases but it was not statistically significant, $3^{\text {rd }}$ Month SNOT scores among CRS with polyp and Allergic fungal sinusitis were decreased as compare to CRS without polyp, but it was not statistically significant, $6^{\text {th }}$ month SNOT scores also went down insignificantly however, at $12^{\text {th }}$ Month SNOT scores in CRS with polyp cases significantly decreased (Table 3).

The most bothersome symptom that reported by the patients was blockage or congestion of nose, at $2^{\text {nd }}$ number decrease sense of taste/smell was reported, at

Table 2. Comparison of Pre-Operative Mean SNOT Scores at Different Follow-ups.

\begin{tabular}{|c|c|c|c|c|c|}
\hline \multirow[t]{2}{*}{ SNOT Score } & \multirow{2}{*}{$\begin{array}{c}\text { Mean } \\
\text { Difference }\end{array}$} & \multirow{2}{*}{$\begin{array}{c}\text { Standard } \\
\text { Deviatio } \\
\mathbf{n}\end{array}$} & \multicolumn{2}{|c|}{$\begin{array}{l}\text { 95\% Confidence Interval } \\
\text { of the Difference }\end{array}$} & \multirow[t]{2}{*}{ p-value } \\
\hline & & & Lower & Upper & \\
\hline Pre Operative Vs. $1^{\text {st }}$ Month & 38.63 & 19.07 & 33.422 & 43.837 & $<0.01^{\star}$ \\
\hline Pre Operative Vs. $3^{\text {rd }}$ Month & 41.05 & 21.09 & 35.298 & 46.813 & $<0.01^{\star}$ \\
\hline Pre Operative Vs. $6^{\text {th }}$ Month & 39.81 & 20.60 & 34.190 & 45.440 & $<0.01^{\star}$ \\
\hline Pre Operative Vs. $12^{\text {th }}$ Month & 39.50 & 20.75 & 33.835 & 45.165 & $<0.01^{*}$ \\
\hline
\end{tabular}

${ }^{*} \mathrm{p}<0.05$ was considered significant using paired Sample t-test.

Table 3. Estimation of SNOT Scores with Diagnosis using Multivariate Generalized Linear Model.

\begin{tabular}{|c|c|c|c|c|c|c|}
\hline \multirow[b]{2}{*}{$\begin{array}{l}\text { SNOT } \\
\text { Scores }\end{array}$} & \multirow[b]{2}{*}{ Parameter } & \multirow[b]{2}{*}{$\begin{array}{c}\text { Beta } \\
\text { Coefficient }\end{array}$} & \multirow[b]{2}{*}{$\begin{array}{c}\text { Standard } \\
\text { Error }\end{array}$} & \multicolumn{2}{|c|}{ 95\% Confidence Interval } & \multirow[b]{2}{*}{ p-value } \\
\hline & & & & $\begin{array}{l}\text { Lower } \\
\text { Bound }\end{array}$ & $\begin{array}{l}\text { Upper } \\
\text { Bound }\end{array}$ & \\
\hline \multirow{3}{*}{$\begin{array}{c}\text { Pre } \\
\text { Operative }\end{array}$} & CRS with polyp & 10.75 & 4.67 & 1.36 & 20.13 & $0.02^{\star}$ \\
\hline & Allergic fungal sinusitis & 32.44 & 5.29 & 21.80 & 43.08 & $<0.01^{*}$ \\
\hline & CRS without polyp & Reference & . & . & . & . \\
\hline \multirow{3}{*}{$1^{\text {st }}$ Month } & CRS with polyp & -0.43 & 1.40 & -3.26 & 2.38 & 0.75 \\
\hline & Allergic fungal sinusitis & 2.67 & 1.59 & -0.53 & 5.87 & 0.10 \\
\hline & CRS without polyp & Reference & . & . & . & . \\
\hline \multirow{3}{*}{$3^{\text {rd }}$ Month } & CRS with polyp & -3.0 & 1.51 & -6.04 & 0.04 & 0.05 \\
\hline & Allergic fungal sinusitis & -2.05 & 1.72 & -5.50 & 1.40 & 0.23 \\
\hline & CRS without polyp & Reference & . & . & . & . \\
\hline \multirow{3}{*}{$6^{\text {th }}$ Month } & CRS with polyp & -2.37 & 1.55 & -5.50 & 0.75 & 0.13 \\
\hline & Allergic fungal sinusitis & -1.71 & 1.76 & -5.26 & 1.83 & 0.33 \\
\hline & CRS without polyp & Reference & . & . & . & . \\
\hline \multirow{3}{*}{$12^{\text {th }}$ Month } & CRS with polyp & -2.70 & 1.34 & -5.40 & -0.01 & $0.04^{*}$ \\
\hline & Allergic fungal sinusitis & -0.89 & 1.52 & -3.94 & 2.16 & 0.56 \\
\hline & CRS without polyp & Reference & . & . & . & . \\
\hline
\end{tabular}

${ }^{*} \mathrm{p}<0.05$ was considered significant. 
$3^{\text {rd }}$ number facial pain/pressure, at $4^{\text {th }}$ number post nasal discharge (PND) and at $5^{\text {th }}$ number runny nose was reported in the study as most frequent. Shown in horizontal bar chart (Figure 2).

Line plot was used to give the trend of SNOT Scores from pre-operative to respective follow-ups, a decline in SNOT scores could be seen with respect to diagnosis (Figure 3).

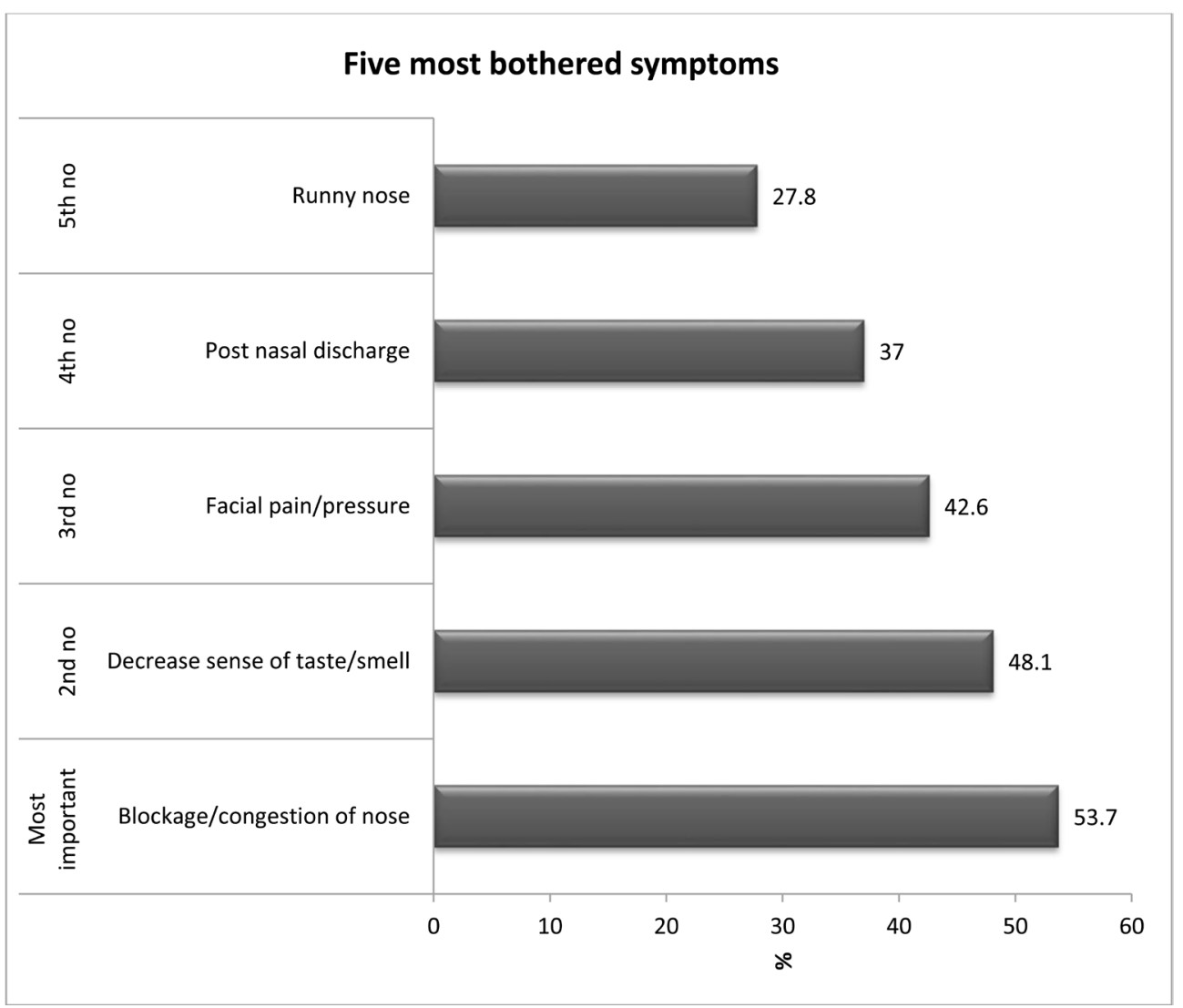

Figure 2. The first five most bothersome symptoms.

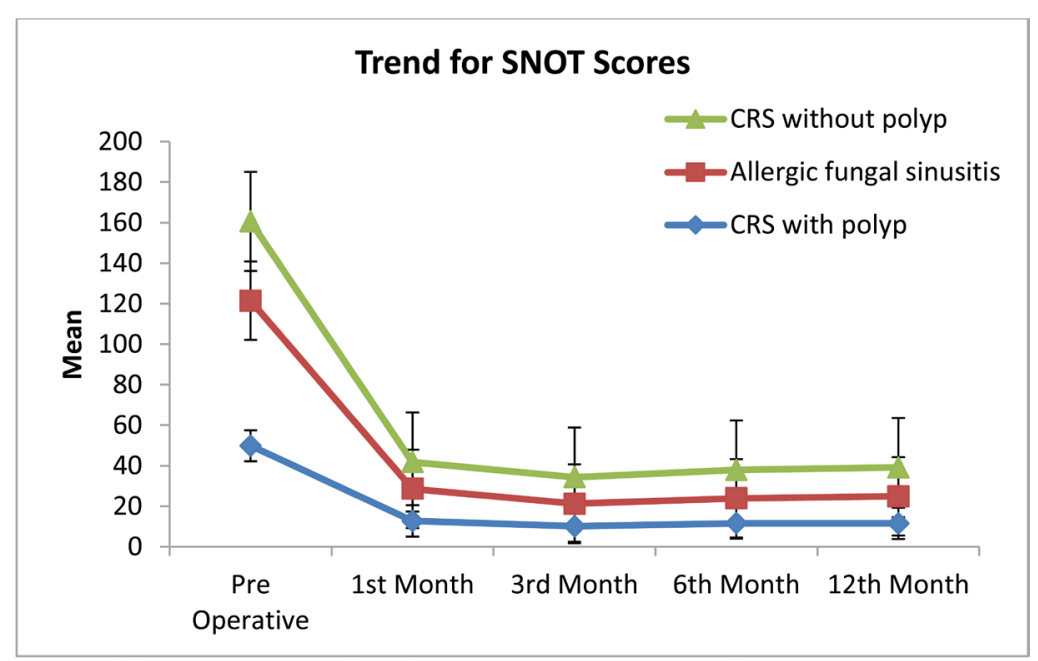

Figure 3. Line plot showing trends of SNOT scores from preoperative to respective follow ups. 


\section{Discussion}

Chronic Rhinosinusitis is a multifactorial morbid disease that affects majority of people [12]. The main goal of management of chronic rhinosinusitis is to eliminate nasal discharge, improve airflow and sense of smell leading to improvement in quality of life of patients. The Functional endoscopic sinus surgery (FESS) has now been gold standard surgical intervention for the patients who failed to respond to medical therapy [13] [14]. Previously, Objective findings have been focused to assess the response to the treatment such as CT scanning and nasal endoscopy. In literature, there has been found that intensity of symptoms experienced by patients did not correlate with radiological findings or nasal endoscopy. This discordance led clinicians to focus on subjective assessment of disease to clearly understand the outcomes after surgery [15]. Therefore, number of disease specific questionnaires have been developed to measure quality of life of the patients such as Chronic Sinusitis Survey (CSS), Rhinosinusitis Disability Index (RSDI), Sino-Nasal Assessment Questionnaire 11 (SNAQ-11) and Sino-nasal outcomes Test (SNOT-22). SNOT-22 is most widely used and validated questionnaire [11] [16]. In our study, we have used the same instrument for assessment of quality of life of patients after surgery.

In our study, male gender was dominant i.e. 59.3\% which is comparable with the literature [17]. Mean age in this study was found to be 35.98 years which is also found closer to other studies [17] [18].

Three subtypes i.e., chronic rhinosinusitis without polyps, chronic rhinosinusitis with polyps and Allergic fungal sinusitis were included. There has been found association of chronic rhinosinusitis with asthma in several studies [19]. Similarly, $22.2 \%$ of patients in our study had previous history of asthma.

The quality of life of patients were assessed in the present study using SNOT-22 scores which were higher in pre-operative period and then reduced significantly in post-operative period. Mean pre-operative SNOT-22 scores were found to be 52.31 which were reduced to $13.69,11.26,12.5$ and 12.81 in post-operative $1^{\text {st }}, 3^{\text {rd }}, 6^{\text {th }}$ and $12^{\text {th }}$ months respectively post intervention. Hopkin et al. [20] also showed significant improvement in mean scores after functional endoscopic sinus surgery from 42 in SNOT-22 before surgery to 25.5 in early post operative period and 27.7 in late post operative period. Preoperative SNOT scores are comparable while in our study, we found further reduction of SNOT scores in post operative period. In another study, Mascarenhas et al. [21] also showed statistically significant improvement in mean SNOT-22 scores from 61.3 to 16.9 in $3^{\text {rd }}$ month and 32.3 in late post operative period. Preoperative and post operative $3^{\text {rd }}$ month SNOT scores of this study was similar to our data but late follow up SNOT-22 scores showed decline in the improvement which is contradictory to our study.

Allergic fungal sinusitis (AFS) group were included in our study along with chronic rhinosinusitis with and without polyps. In the literature, Allergic fungal sinusitis group was not compared mostly in the literature with the other two 
common subtypes [22]. Masterson et al. [23] compared the three subtypes and their results showed that AFS group showed significant improvement at $12^{\text {th }}$ month when compared with chronic rhinosinusitis without polyps while our results of the model showed further improvement in patients with chronic rhinosinusitis with polyps at one year.

In our study, the first five most bothersome symptoms were nasal blockage or congestion (53.7\%), decrease sense of smell or taste (48.1\%), facial pain (42.6\%), post nasal discharge (37\%) followed by rhinorrhea (27.8). Damm et al. [14] showed nasal obstruction (94\%) as most frequent complain. Headache was also one of the main complains in that study which was not seen in our study. Simiarly, Mishra et al. [24] showed nasal blockage as most bothered symptom. This data helps in identifying the most frequent subjective complaints by patients which need to address on prior basis.

Single institution based study is the limitation while inclusion of all the major sub types of chronic rhinosinusitis for assessment of quality of life is the strength of the study.

\section{Conclusion}

This study supported that functional endoscopic sinus surgery (FESS) is the best surgical intervention for chronic rhinosinusitis. It provides significant improvement in the quality of life of patients in all the three subgroups of chronic rhinosinusitis which can be assessed by using SNOT-22 questionnaire.

\section{References}

[1] Vaid, L., Khanna, S. and Singh, P. (2007) Impact of Nasal Polyps on Quality of Life of Chronic Sinusitis Patients. Indian Journal of Otolaryngology and Head \& Neck Surgery, 59, 136-141. https://doi.org/10.1007/s12070-007-0040-3

[2] Chan, Y. and Kuhn, F.A. (2009) An Update on the Classifications, Diagnosis and Treatment of Rhinosinusitis. Current Opinion in Otolaryngology \& Head and Neck Surgery, 17, 204-208. https://doi.org/10.1097/MOO.0b013e32832ac393

[3] Voegels, R.L. and de Melo Padua, F.G. (2005) Expression of Interleukins in Patients with Nasal Polyposis. Otolaryngology-Head and Neck Surgery, 132, 613-619. https://doi.org/10.1016/j.otohns.2005.01.014

[4] Fokkens, W., Lund, V. and Mullol, J. (2007) European Paper on Rhinosinusitis and Nasal Polyps Groups. Rhinology. Supplement, No. 20, 1-136.

[5] Meltzer, E. and Hamilos, D. (2011) Rhinosinusitis and Management for the Clinician: A Synopsis of Recent Concensus Guidelines. Mayo Clinic Proceedings, 86, 427-443. https://doi.org/10.4065/mcp.2010.0392

[6] Bhattacharyya, N. (2004) Symptom Outcomes after Endoscopic Sinus Surgery for Chronic Rhinosinusitis. Archives of Otolaryngology_Head and Neck Surgery, 130, 329-333. https://doi.org/10.1001/archotol.130.3.329

[7] Alobid, I., Bernal, S.M., et al. (2008) Chronic Rhinosinusitis and Nasal Polyps: The Role of Genric and Specific Questionnaires on Assessing Its Impact on Patients's Quality of Life. Allergy, 63, 1267-1279.

https://doi.org/10.1111/j.1398-9995.2008.01828.x 
[8] Ehnhage, et al. (2011) One Year after Endoscopic Sinus Surgery in Polyposis: Asthma, Olfaction and Quality of Life Outcomes. Otolaryngology-Head and Neck Surgery, 146, 834-841. https://doi.org/10.1177/0194599811435638

[9] Bezerra, T., et al. (2012) Assessment of Quality of Life after Endoscopic Sinus Surgery for Chronic Rhinosinusitis. Brazilian Journal of Otorhinolaryngology, 78, 96-102. https://doi.org/10.1590/S1808-86942012000200015

[10] Marambaia, P.P., Lima, M.G., Santos, K.P., et al. (2013) Evaluation of Quality of Life of Patients with Chronic Rhinosinusitis by Means of the SNOT-22 Questionnaire. Brazilian Journal of Otorhinolaryngology, 79, 54-58. https://doi.org/10.5935/1808-8694.20130010

[11] Hopkins, C., Gillett, S., et al. (2009) Psychometric Validity of the 22-Item Sinonasal Outcome Test. Clinical Otolaryngology, 34, 447-454. https://doi.org/10.1111/j.1749-4486.2009.01995.x

[12] Brett Cherry, W. and Li, J.T. (2008) Chronic Rhinosinusitis in Adult. The American Journal of Medicine, 121, 185-189. https://doi.org/10.1016/j.amjmed.2007.09.022

[13] Halawi, A.M., Smith, S.S. and Chandra, R.K. (2013) Chronic Rhinosinusitis: Epidemiology and Cost. Allergy \& Asthma Proceedings, 34, 328-334.

https://doi.org/10.2500/aap.2013.34.3675

[14] Damm, M., Quante, G., Jungehuelsing, M. and Stennert, E. (2002) Impact of Functional Endoscopic Sinus Surgery on Symptoms and Quality of Life in Chronic Rhinosinusitis. Laryngoscope, 112, 310-315. https://doi.org/10.1097/00005537-200202000-00020

[15] Stewart, M.G. and Smith, T.L. (2005) Objective versus Subjective Outcomes Assessment in Rhinology. American Journal of Rhinology, 19, 529-535.

[16] De Conde, A.S., Mace, J.C., Bodner, T., et al. (2014) SNOT-22 Quality of Life Domains Differentially Predict Treatment Modality Selection in Chronic Rhinosinusitis. International Forum of Allergy \& Rhinology, 4, 972-979. https://doi.org/10.1002/alr.21408

[17] Nikakhlagh, S., Bakhshi, A. and Noroozi, S. (2015) Evaluation of Quality of Life of Patients with Chronic Rhinosinusitis before and after Endoscopic Sinus Surgery. Biomedical and Pharmacology Journal, 8, 73-77.

[18] Nair, S., Dutta, A., Rajagopalan, R. and Nambiar, S. (2011) Endoscopic Sinus Surgery in Chronic Rhinosinusitis and Nasal Polyposis: A Comparative Study. Indian Journal of Otolaryngology and Head \& Neck Surgery, 63, 50-55. https://doi.org/10.1007/s12070-011-0119-8

[19] Lam, K., Hirsch, A.G. and Tan, B.K. (2014) The Association of Premorbid Diseases with Chronic Rhinosinusitis with and without Polyps. Current Opinion in Otolaryngology \& Head and Neck Surgery, 22, 231-241. https://doi.org/10.1097/MOO.0000000000000052

[20] Hopkins, C., Browne, J.P., Slack, R., Lund, V., Topham, J., Reeves, B., et al. (2006) The National Comparative Audit of Surgery for Nasal Polyposis and Chronic Rhinosinusitis. Clinical Otolaryngology, 31, 390-398. https://doi.org/10.1111/j.1749-4486.2006.01275.x

[21] Mascarenhas, J.G., Fonseca, V.M.G., Chen, V.G., et al. (2013) Long Term Outcomes of Endoscopic Sinus Surgery for Chronic Rhinosinusitis with and without Polyps. Brazilian Journal of Otorhinolaryngology, 79, 306-311. https://doi.org/10.5935/1808-8694.20130055

[22] Champagne, J.P., Antisdel, J.L., Woodard, T.D. and Kountakis, S.E. (2010) Epidemiologic Factors Affect Surgical Outcomes in Allergic Fungal Sinusitis. Laryngos- 
cope, 120, 2322-2324. https://doi.org/10.1002/lary.21127

[23] Masterson, L., Ergo, F.M., Bewick, J., et al. (2016) Quality of Life Outcomes after Sinus Surgery in Allergic Fungal Rhinosinusitis versus Nonfungal Chronic Rhinosinusitis. American Journal of Rhinology \& Allergy, 30, 30-35.

https://doi.org/10.2500/ajra.2016.30.4280

[24] Mishra, D.K., Bhatta, R. and Verma, L.R. (2010) Quality of Life after Functional Endoscopic Sinus Surgery. Nepalese Journal of ENT Head and Neck Surgery, 1, 6-8. 